HELDA 


\title{
Inclusive Education in the diversifying environments of Finland, Iceland, and the Netherlands: A multilingual systematic review
}

\begin{abstract}
This review investigates how the scholarly fields, themes, and concepts of

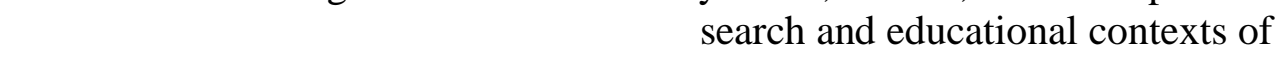
Finland, Iceland, and the Netherlands. It identifies and outlines which thematic areas of research and sub-fields of study are referenced in each country by applying a systematic, multilingual approach. We reviewed literature in the local languages of each of these countries over the past decade, from 2007 to 2018, paying particular attention to (1) micro-level, in-depth, classroom interactions, (2) social and political contexts, and (3) social categories. Results of this review emphasise that across all three countries (a) there are similar conceptualisations of inclusive education dominated by categories of disability and special needs, and (b) there is a similar lack of attention to modes of exclusion based on social class, gender, ethnicity and geography as well as to how these can be addressed by more advanced research on inclusive education in these local spheres.
\end{abstract}

Keywords: Inclusion, inclusive education, multilingual review, Northern Europe, educational access, intersectionality, comparative research

\section{Introduction}

Over the last decade, a considerable number of studies in educational sciences have focused on inclusive education. Within Western scholarly literature, inclusive education has become a concept subject to much debate. It has also been approached via diverse epistemologies, ranging from the positivist medical model to more critical research models that are sensitive to the institutional and socio-cultural contexts (Allan and Slee, 2008). Inclusive education originated as a rebellion against special schools for children identified as disabled, asserting a strong critique against medical and psychological explanations of disability (Gibson, 2015). Slee (2013) has argued that $\ddagger$ special schools exist because of the failure of regular schools·, stating that łto push kids into an unreconstructed regular school system is highly (as has been proven) problematic. (p. 905). Furthermore, Hardy and Woodcock (2015) and Gibson (2015) underline the 
importance of student (intersectional) identities for understanding inclusion and educational justice, as inclusive policies globally often reflect neoliberal policy positions that risk failing to provide sufficient opportunity and support for students prone to exclusion. Meanwhile, segregation and inequality are exacerbated by social class and geographical location, exposing a need to broaden the inclusion concept to encompass issues of structural exclusion as well (Barton, 2004; Mittler, 2008).

Similarly, inclusion without an intersectional approach carries the danger of falling in line with the older frameworks of schooling, such as monocultural schooling with a dichotomy of abled or disabled students.

Considering how marketisation and neoliberal policies increase institutional discrimination by concentrating disadvantaged families and students with special needs within the same institutions (Dudley-Marling and Baker, 2012; Magnússon, 2019), there is an urgent need to problematise social diversification across schools that tends to be marginalised within inclusive educational research literature (Artiles, Kozleski, \& Waitoller, 2011; Berhanu \& Dyson, 2012; Cooc \& Kiru, 2018). Often when discussing social and educational inclusion, the gaze turns towards Northern European countries, which persistently appear as ideal in ongoing debates about inclusion, access, and equity in education (e.g., Hienonen et al., 2018). Yet due to the fragmentation of research literature in local languages, there is a limited understanding of what inclusive education means and what kind of inclusive educational research is common in these countries, in spite of the fact that a good deal of the existing literature is republished, or solely published, in English. This systematic review is an effort to address the issue of what may be lost or overlooked in translation by identifying how the concept of LQFOXVLYHHGXFDWLRQILVGLVFXVVHGLQWKHQDWLRQDOVFKRODUOIGHEDWHVLQ European countries, namely Finland, Iceland, and the Netherlands. 


\section{Meta-analysis of Localised Perspectives on Inclusive Education}

\section{)RUPRUHWKDQDGHFDGH(QJOLVKODQJXDJHOLWHUDWXUHKDVVKRZQWKDWWKHUHL}

assumption that inclusion is primarily about educating disabled students, or those

FDWHJRULVHGDVKSHHL(DOHGXFDWLRQDOQHHGILQPDLQVWUHDPVÆKKROV·\$LQVFRZ

al., 2006: 15). Lately, this has been challenged, and there is a need for expanding the definition to acknowledge all groups of pupils in danger of systematic exclusion (Artiles et al., 2011). During the past decade, the intersectional approach has been popular when discussing the groupings and/or categorisations of pupils as well as the range of possibilities for exercising educational choice. Intersections of social categories such as social class, ethnicity, and gender in educational sociology exert power in the field of education (e.g. Francis et al., 2019; Reay, Crozier \& James, 2011; Vincent et al., 2013). This suggests that inclusive education, as a concept, can be applied broadly. We explore whether broader definitions of inclusion (Artiles, Kozleski and Waitoller, 2011) are represented in the local academic discussions around inclusive education in Finland, Iceland, and the Netherlands.

There is recent research showing support for broadly inclusive policies (O'Rourke, 2015), but typically these are not based on consistent conceptual frames. Meta-analyses of research on inclusive education do exist (Göransson and Nilholm, 2014), with some studies focusing specificalOIRQLQFOXVLYHHGXFDWLRQ'HOOI\$\$QQD Pellegrini, \& Ianes, 2019; Van Mieghem, Verschueren, Petry, \& Struyf, 2020), and also with multilingual methodologies (Amor et al., 2019). Nonetheless, they are somewhat disparate and few are focused on how researchers have investigated the phenomenon of inclusive education. Despite the limited explorations of research across multiple linguistic and cultural contexts, the relevance of comparative systematic findings about the local level has implications for reframing the ways in which inclusion as a travelling 
policy and the so-called 'evidence-based' policies are constructed and applied in local contexts. Inclusive education, in research and in practice, is ultimately a concern with social justice both locally and globally, and, as Waitoller and Artiles (2013: 322) have argued, inclusive education should strive for $\ddagger \quad$ UHGLVWULEXWLRQRIDFFHVV «WKH

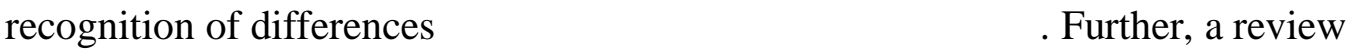
perspective redirects attention to the idea that educational exclusion is the result of a host of interacting factors requiring complex responses from teachers, researchers, citizens and (inter)national policy makers.

\section{Comparability of National Contexts}

When applying Gita Steiner-.KDPVLIIVFRQFHSWXDOLVDWLRQRIFRQGXFWLQJ comparative research, or in this case contrastive research, we acknowledge that we are comparing different schooling systems. For our analysis, we have chosen Finland, Iceland and the Netherlands, which, despite being commonly considered as fairly egalitarian and as having shared cultural affinity as Northern European countries, have crucial differences in relation to inclusive aims and practices in education. Our analysis spans the years 2007 to 2018, a time period which has carried significant changes in inclusive education in each of these case countries. Each country has committed to international agreements that aim for inclusive education, such as the 8QLWHG1DWLRQVII\&iBudrite Rights of Persons with Disabilities, which was DGRSWHGLQDQGUDWLILHGEIDOOFDVHFRXQWULHVODWHLQWKHV\$OOWKUHHFRXQV national educational policies have also been adjusted and reframed in accordance with inclusive aims.

The Netherlands is a more ethnically diverse society than Finland and Iceland given the relatively high numbers of inhabitants with migrant backgrounds, and it has a 
rather long history of debating questions around migration within the sphere of educational sciences (Rezai et al., 2015; Van De Werfhorst and Van Tubergen, 2007). The Dutch education system is often characterised as KLJKOIVWUDWLILHGI9DQ' $H$ :HUIKRUVWDQG9DQ7XEHUJHQRUKLJKOIWUDFNHGII.ORRVWHUPDQDQGGH

Graaf, 2010: 381). In contrast, the Finnish education system is considered egalitarian,

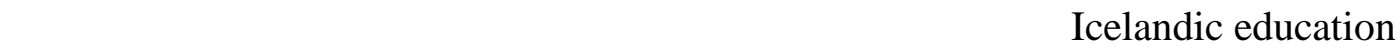
system is similarly comprehensive with a strong emphasis on inclusion (Sigurðardóttir et al., 2014).

Yet similar patterns of neighbourhood and school segregation that have been recently reported in the Netherlands (Boterman, 2018), are emerging on a smaller scale in Finland (Bernelius and Vaattovaara, 2016; Bernelius and Vilkama, 2019) and Iceland (Authors). Meanwhile, there are indications that social and educational divisions are also widening in Iceland (Dovemark et al., 2018; Lundahl, 2016; Authors) despite egalitarian policies being in place for the past three decades (Marinósson and Bjarnason, 2014). In summary, although all three countries wrestle with questions of widening social inclusion and exclusion, their approach to inclusion appears as a spectrum of policy and outcomes (see Table 1), and the inclusive practices vary between all three case countries.

The Netherlands relies primarily on early tracking and standardised testing, which can be problematic from an inclusion point of view (Ainscow et al., 2006; Hamre et al., 2018), whereas Iceland aims, at least officially, for a completely inclusive approach to education (referred to as skóli fyrir alla - school for everyone). Finland falls somewhere in between Iceland and the Netherlands (see table 1 and figures 1 and 2). Despite its long history of an egalitarian educational system, there is evidence that 
pupils experience insufficient support and systemic inequality in Finland, and schools have persistently resorted to separate teaching for students with special needs until fairly recently (Authors, 2020; Authors, In press).

\begin{tabular}{|l|l|l|l|}
\hline & The Netherlands & Finland & Iceland \\
\hline $\begin{array}{l}\text { Education system } \\
\text { stratification }\end{array}$ & High & Low & Very low \\
\hline $\begin{array}{l}\text { Widening } \\
\text { inequality/segregation }\end{array}$ & Advanced & Early & Very early \\
\hline Inclusion policy & Low & Low/Medium & High \\
\hline
\end{tabular}

Table 1. Country typology - education systems, indications of inequality and inclusion.

Thus, the outcomes regarding social inclusion and inequalities in the social and educational system seem to be moving in similar directions in all three Northern European case countries, despite clear differences at the macro level of their educational systems.

By and large, a crucial principle within the Finnish education system has been that all children are expected to receive basic education, along with any additional required support, in their local neighbourhood schools. This idea dates back to the 1970s when comprehensive schooling was introduced to provide one school for all, against system-level marginalisation, exclusion, and banding in mathematics and foreign languages. Hence, a form of ability grouping and early tracking (Authors, 2017) was abolished in the 1980s (Antikainen, 2006; Ahonen, 2003). Although the Finnish comprehensive school became fairly uniform, at least officially, in the 1990s, the emergence of school choice policy among public schools (Authors, 2003), particularly inside the schools (Authors, 2017; Authors, 2016), along with urban segregation 
(Bernelius, 2013) segmented the system. The most recent and significant reform affecting inclusion is the three-tiered framework of support from 2010. The reform aims toward inclusive education as it has changed the way special education is understood and organised within schools, but there are varying practices between schools (Ahtiainen, 2017).

The Icelandic policy of inclusive education has evolved from one based on speciDOQHHGVDQGPRGHOVRIGLVDELOLWרWRZDUGVRQHWKDWUHIOHFWVWKHLGHDR of diversity’ (skóli margbreytileikans). This evolution draws from a set of values relating to educational equality, social justice, and human rights (Halldórsdóttir et al., 2016). The School of Diversity is characterisHGDV $\$ \ll D U H J X O D U V F K R R O W K D W P D N H V U R R P$ for all the students from a neighborhood, a school where teachers and other staff work WRJHWKHUWRJLYHHDFKDQGHYHUIVWXGHQWWKHEHVWSRA\&dLEZOH,HGXFDWLRQ.\%M 2016: 356). This evolution can also be seen as a response to recent policy changes (Marinósson \& Bjarnason, 2014) in line with neoliberal educational imperatives.

Figure 1. Percentage of pupils with an official decision of SEN in inclusive education, based on the population of pupils with an official decision of SEN (\%), derived from the European Agency for Special Needs and Inclusive Education 2017

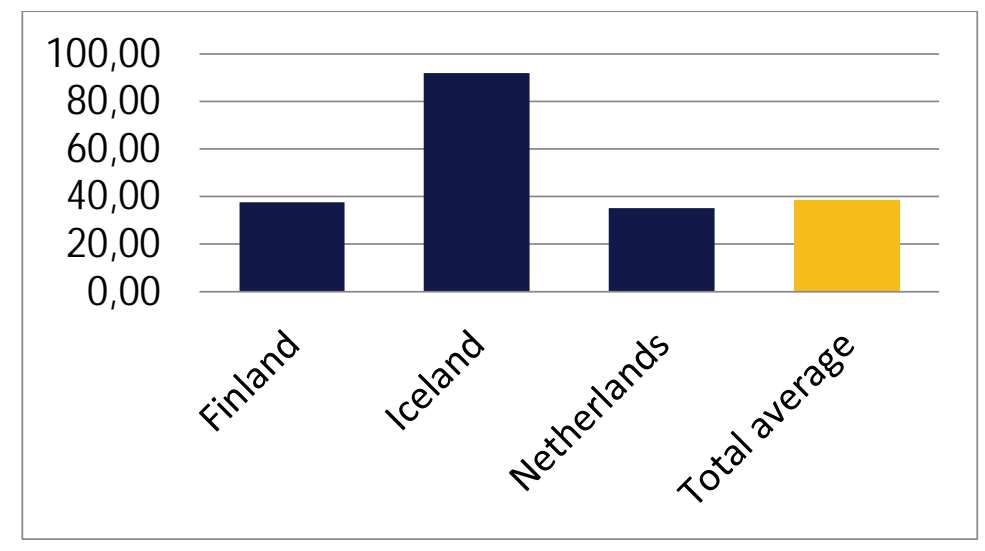


Figure 2. Percentage of pupils with an official decision of SEN in special schools, based on the population of pupils with an official decision of SEN (\%), derived from the European Agency for Special Needs and Inclusive Education 2017.

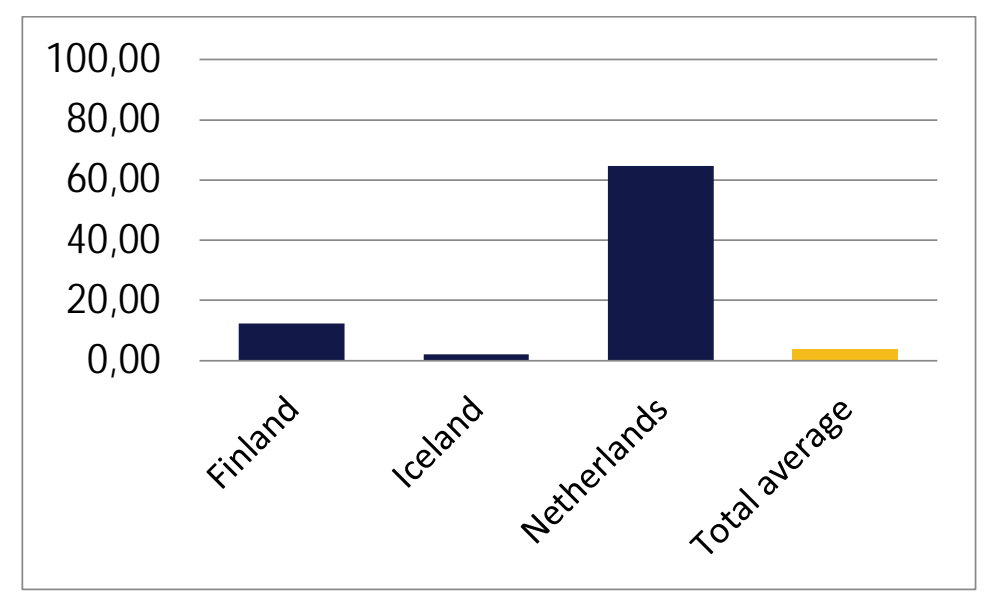

\section{This Study}

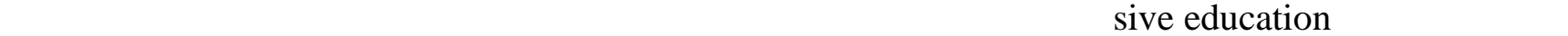

is applied and understood in the national research contexts of Finland, Iceland and the

Netherlands between 2007 and 2018. This past decade is a useful period to investigate

as there has been more than enough time since the Salamanca Statement (UNESCO 1994) to both implement inclusive education policies and see their effects. As there are various and multiple meanings and definitions attached to the concept of inclusion (Amor et al., 2018), the Salamanca Statement has become an obligatory reference in any research on inclusion nowadays, particularly since its targets have evolved and EHFRPHPRUHDOLJQHGZLWK81(6\&2IVFRQWHPSRUDUIDLPVVXFKDV7KH6XVWDLQDEOH

Development Goals which emphasise inclusion and equity for education in 2030

(UNESCO, 2015). Different strands within academia can construct their place within the concept. Discerning these constructions is relevant for capturing the current state of affairs and for considering how different national research communities have understood this concept and interpreted this policy over the last 10 years. 
The main goal of this review is to concentrate more closely on the local scholarly debates regarding inclusive education in Finland, Iceland, and the Netherlands, and determine to what extent the broader scholarly conceptualisations of inclusive education have appeared in these countries in relation to international literature (Allan and Slee, 2008; Artiles et al., 2011; Slee, 2011). We consider whether the expanding meaning and understanding of inclusive education has gained attention within the educational research domains in these three countries. Such an overview is currently absent because national research publications primarily report in the local language, subsequently falling outside the consideration of the international research community. To overcome this linguistic barrier, our review and analysis is based on a multi-step multilingual systematic review approach (Mazenod, 2018) in which studies concerning each specific case country are reviewed in the local language(s). This review is part of a larger effort to understand and reconceptualise inclusive education specifically at macro (e.g., national and regional policy) and micro (e.g., classroom interactions) levels of different educational systems. We focus on the micro and macro levels by drawing from Waitoller and Artiles (2013: 322), who emphasise the

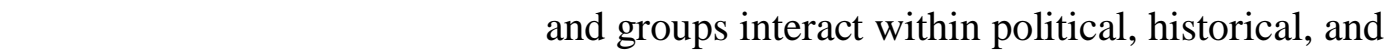
sociocultural contexts (i.e., a constant interaction and relationship of micro and macro SURFHVV.

It is important to distinguish the concepts of special and inclusive education, especially since they are often used misleadingly as synonyms. During the past few decades, inclusive education has been broadened to encompass a notion of education for

\footnotetext{
${ }^{1} \mathrm{We}$ are not implying that the meso level is less important. Rather, for the purposes of this UHYLHZIVGHVLJQDQGIRFXVZHFRQVLGHUWKDWWKHPLFURDQGWKHPDFUROHYHOVDQGWKH relationship) are more suitable analytically.
} 
all. There has been a shift from support and placement of pupils that are defined as having special needs to a principled approach to education and society that deals with DOOSXSLOVIDFFHVVDQGVXSSRUW81(6\&2IRUH[DPSOHVWDWHVWKDW

Inclusion and equity in and through education is the cornerstone of a transformative education agenda, and we therefore commit to addressing all forms of exclusion and marginalization, disparities and inequalities in access, participation and learning outcomes. (UNESCO, 2015: 7)

Despite this conceptual change, the theoretical principle behind special education is often still aimed at identifying students who fall outside the margins of normal distribution and providing them with support that those in the center of the bell curve do not need (Florian, 2019; Richardson and Powell, 2011).

The sociological factors shaping the processes of special education as the SEN industryIf is related to the economic and power structures in societies, and thereby favours those with more affluent backgrounds (Tomlinson, 2017). As at many levels there is still conceptual obscurity between the concepts of special and inclusive education, it makes educational policies, practices and research complicated and incoherent (Florian, 2019, Richardson and Powell, 2011; Waitoller and Artiles, 2013).

The obscurity that connects inclusive and special education maintains that LQFOXVLYHHGXFDWLRQLVRIWHQGHILQHGWKURXJKWKHTXHVWLRQRIZKHWKHU‡SX VSHFLDOQHHGV·RUGLVDEOHGSXSLOVKDYHWKHVDPHDFFHVVDQGSRVVLELOLWIWRI neighbourhood schools as children that have not been identified as having special needs (Ainscow et al., 2006; Waitoller and Artiles, 2013). This narrow definition has received substantial critique in the research literature due to its lack of sociological and intersectional understanding (Waitoller and Artiles, 2013; Thomas, 2013; Raffo and Gunter, 2008). It concentrates on the perceived deficits of the individuals and reduces 
problems to something that can be changed by changing the individual instead of concentrating on the wider social inequalities and structures. The intersecting disadvantages are therefore not being acknowledged.

Florian (2019) and Richardson and Powell (2011) suggest we go a step further and give up on dichotomies and categorisations in education altogether by acknowledging that social categories pose problems only in relation to the applied policies and practices. Especially if schooling is organised for the normative center of the bell curve, it reproduces marginalisation and exclusion by default (Florian 2019). Richardson and Powell (2011: SRLQWRXW $\$ 5 H V H B U$ HFdkds to examine diverse KLVWRULFDODQGFXOWXUDOXQGHUVWDQGLQJVRIVWXGHQWGLVDELOLWIIDQGVSH QHHGVIDVZHOODVWKHVFKRROVWGKEWOHUH

In this review, we analyse how research published in local languages defines and uses the concept of inclusive education across three linguistic contexts. Although much inclusive education research is conducted internationally in English, non-English studies can be both approachable and influential locally. We pay particular attention to whether and how a sociological and intersectional understanding guides the research settings in the local contexts, or whether the narrow definition that emphasises special needs is as dominant as previous research has indicated (Waitoller \& Artiles, 2013).

More specifically, we summarised the extent to which the literature on inclusive education in these three countries focuses on: (1) classroom interactions, (2) sociopolitical contexts, and (3) social categories. Although we acknowledge the need to move beyond categories, we simultaneously assume that in many cases the definition and use of the inclusive education concept is narrowly focused on a single category, namely that of special learning needs. Analysis of socio-political contexts and categories, such as ethnic minority groups or socio-economic status, focuses on the 
extent to which inclusive education is understood as education for all rather than as a question of the placement and measures targeted for pupils defined as disabled or with special needs. Examination at the micro-level of schooling practices is considered in relation to the larger socio-political context and, among other things, social stratification (Richardson \& Powell, 2011). On the other hand, if we take seriously the need to understand the micro level in relation to the macro level and strive to avoid discrepancies between the two, examination of micro-level practices and interactions can be a key element of inclusive education research. Therefore, we also investigate the extent to which existing local-language research on inclusive education provides an indepth analysis of interactions at the micro-level.

Our review process investigates and compares the national academic literature across three languages. A key consideration was to examine how ideas, social and political changes in the societies over the past decade were reflected in WUDYHOLQJ SROLFLHOygga and Jones, 2006), which materialise not only in practice, but also in the conceptualisations of research themes and topics. Travelling policies have the aim of WUDQVIHUULQJEHVWIINQRZOHGJHARA WWRAWd(based knowledge) between

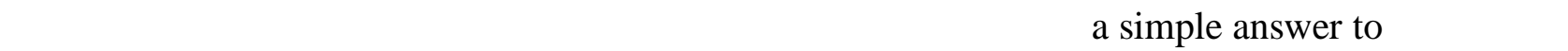
an ever-growing competition. Travelling policies have been integrated in all countries, EXWDUHIRXQGGLIIHUHQWOYIISORHVDVJOREDODJHQGDVFDQFRPHXSDJDLQVW existing priorities and practices. Travelling policies can therefore instead become HPEHGGHGIISROLthatHherely reflect local priorities and meanings (Ozga and Jones, 2006).

We compared the similarities and differences within the Finnish, Icelandic, and Dutch contexts and propose new avenues for research based on the findings. This systematic review contributes to the need for localised perspectives within inclusive 
education research by (a) examining how inclusive education is defined and applied across three different local contexts, and (b) outlining which thematic areas of research and sub-fields of study are referred to in Finland, Iceland and the Netherlands. The primary question addressed in this systematic review is: + RZLVWKHWHUPLQFOXVLYH

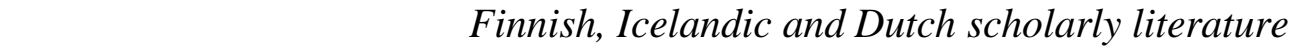
between 2007 and 2018?

\section{Methods}

\section{Data Collection}

Inspired by previous systematic reviews on inclusive education, our data consists of scientific peer-reviewed articles, books, and dissertations published in local languages (Van Mieghem et al., 2020; 'HOOI\$QQDal., 2019). We drew from Amor et al. (2018) particularly as we were conducting a multilingual review (although bilingual in their case), conducting our searches parallel to each other ( $p$ 1280). However, in contrast to Amor and colleagues, who worked with themes and several terms, we only focused on a two-word term, LQFOXVLYHHGXFDWLRQIDQGWUDQVODWHGLWLQWRDOOWKUHHODQJ choice made our systematic review both narrow and broad: narrow in the sense of focusing on one main concept (inclusive education), and broad in the sense of allowing us to review studies that tackle the concept from diverse disciplinary, epistemological, and methodological viewpoints.

\section{)LUVWZHFRQVLGHUHGYDULLQJGHILQLWLRQVDQGSKUDVHVIRULQFOXVLYHH}

existing within the national scholarly discourse to identify the availability of research conducted in the local language per country. Next, we considered how the concept of inclusive education is studied in all three national contexts, determined the context of the research and the methodological approaches employed, and identified the primary 
themes by summarising the extent to which the literature in these three countries focused on classroom interaction , socio-political context , and social categories. To overcome possible inconsistencies in translating terminology across three different languages, we used the most common translation of the term inclusive education' in Finnish, Icelandic, and Dutch.

The Boolean algorithm applied in the three contexts is $¥ L Q N O X X V L R$. $¥ L Q N O X V E L^{2} Y L$ for Finland, $¥ V N y O L i Q D E J U H L Q L Q$ fWDLeland, and $\$ L Q F O X V L H I$ RQGHUZLFEV the Netherlands (see table 2 for the databases). Although we acknowledge that applying additional search terms in each national context (e.g. explicitly searching for intersectionality or diversity in education) would have resulted in a larger data set to review, we chose to restrict our search to one comprehensive term, DVWKHDLPRIRXUUHYLHZZDVWRLQYHVWLJDWHKRZWKHWHUPLQFOXVLYHHGXFDWI applied across research contexts to capture the wider scholarly discourse. Additionally, the Boolean algorithms of the databases extend to terms that are catalogued with or FORVHOIUHODWHGWRWKHWHUPLQFOXXVYHHGXFDWLRQI

\begin{tabular}{|c|c|c|c|}
\hline & The Netherlands & Finland & Iceland \\
\hline Databases & $\begin{array}{l}\text { Google Scholar; } \\
\text { ERIC; NRO; } \\
\text { WorldWideScience; } \\
\text { UvA CataloguePlus; } \\
\text { PiCarta; NARCIS; } \\
\text { Pedagogische } \\
\text { Studies, and } \\
\text { WorldCatDiscovery }\end{array}$ & $\begin{array}{l}\text { ARTO, Finna, } \\
\text { Melinda, and } \\
\text { FRANK }\end{array}$ & $\begin{array}{l}\text { Leitir, Skemman, } \\
\text { Gegnir, Opin } \\
\text { Vísindi, EBSCO, } \\
\text { ERIC, Scopus, } \\
\text { Web of Science, } \\
\text { Sage, ProQuest, } \\
\text { and Wiley }\end{array}$ \\
\hline
\end{tabular}

Table 2. Searched databases per country.

\footnotetext{
${ }^{2}$ The * in this term stands for varying endings of this word stem, inklusiivinen or inklusiivisen.

${ }^{3}$ 7KHWUDQVODWLRQVXVHGIRUWKLVVIVWHPDWLFUHYLHZSDUDOOHOWKHWUDQVODWLRQ HGXFDWLRQTIOLVWHGLQ7(6(WKHWKHVDXUXVIRUHGXFDWLRQVIVWHPVLQ(XURSHDYDLODEC http://data.europa.eu/88u/dataset/tese-the-thesaurus-for-education-systems-in-europe-2009edition
} 
The screening process involved identifying scientific literature in local language(s), reviewing the abstracts and introductions to extract a definition of inclusive educationI, and finally, a detailed reading of specified sections of the literature to evaluate the research focus within each national context. The time span for the publication search was 2007-2018 in all countries. Both scientific peer-reviewed articles and books were included. Dissertations were captured and reviewed in the Finnish and Dutch languages, but were excluded from the Icelandic data because doctoral students in Iceland are obliged to publish in English, apart from a summary written in Icelandic.

\section{Analysis}

After we summarised the data extracted for review, it was organised into two sets of tables per country to provide a clear summary of the definitions, orientation, and conceptualisations associated with the term inclusive education in each country (see Supplemental Tables). We compared tabulated datasets to verify that the established search protocol and analytical review procedure was the same in all three countries, thus supporting comparison across countries. The last step in the review process before interpreting the results was a qualitative analysis of particular elements of the inclusive education research (see table 3).

This last step was guided by three analytical questions: 1) what kind of interactions (classroom level, individual learning, social praxis, etc.) were focused on in the research; 2) how the research was framed regarding the social, political and demographic context of the education system and its surrounding community, and in terms of national and international policy; and 3) which social FDWHJRULHVVXFKDVVSHFLDO 
HGXFDWLRQDOQHHGVIRURLefERßWghto account in the examined studies. Answers for all three questions were drawn from a rigorous reading of Keywords, Introduction, and Methods sections of all reviewed publications.

Table 4 contains the final count of collected sources for the study data

\begin{tabular}{|l|l|l|l|}
\hline & $\begin{array}{l}\text { Exploration of } \\
\text { interactions }\end{array}$ & $\begin{array}{l}\text { Socio-political } \\
\text { contexts }\end{array}$ & Social categories \\
\hline $\begin{array}{l}\text { Sections } \\
\text { analysed }\end{array}$ & Methods/Intro & Methods/Intro & Keywords/Methods/Intro \\
\hline
\end{tabular}

Table 3. Sections reviewed within the studies.

\begin{tabular}{|l|l|l|l|}
\hline & The Netherlands & Finland & Iceland \\
\hline $\begin{array}{l}\text { Peer-reviewed } \\
\text { articles }\end{array}$ & 10 & 13 & 12 \\
\hline Books & 13 & 9 & 10 \\
\hline Dissertations & 2 & 12 & 0 \\
\hline Total & 25 & 34 & 22 \\
\hline
\end{tabular}

Table 4. Yielded results from the reviewing process.

\section{Results}

Below we describe (a) how inclusive education is defined and applied in the Finnish, Icelandic, and Dutch contexts, and (b) the ways in which inclusive education research themes are referred to in terms of interactions, social contexts, and particular soci al categories within these local contexts. 


\section{Inclusive Education Concepts in Academic Literature in Three National}

\section{Contexts}

\section{Finland:}

In the research literature dealing with inclusive education in Finland (13 articles, 9 books and 12 dissertations), inclusion is mainly understood as participation or as an attitude promoting communities and one school for all children. The general research concepts comprise inclusive and exclusive practices; difference-making in categorising students; (neighbourhood) school allocation; definition of concepts related to inclusion; VFKRROFXOWXUHDQGHQYLURQPHQWWHDFKHUVIDWWLWXGHVWH[WERRNVUHODW education; case-studies of special needs children in mainstream and special education; encountering diversity in schools and classrooms; educational paths of children; inclusion in policy documents and politics, and their implications for practices; participation and belonging, i.e., inclusion as participation in school and the larger society; and inclusion and quality of learning.

Many of the Finnish studies explore actual interactions within schools. Particularly in dissertations, interest in interactions is linked to ethnographic methodologies. Interactions referenced in journal articles were explored exclusively in papers based on dissertation research, with only one exception. In 13 of the 21 books and dissertations, the data is provided through observations. These include edited books in which at least in some of the chapters, the data is based on observations. Nine of the publications examining actual interactions within classrooms or schools are dissertations. This may be because time- and resource-intensive ethnographic work is tenable in the course of completing PhD studies, but more difficult in other research projects.

Concerning how the studies deal with the larger socio-political context, the political context is usually framed within the national legislation, such as the National Core Curriculum and the Basic Education Act (BEA 628/1998; BEA 642/2010) and/or international agreements to which Finland is committed, such as the Salamanca Statement. Again, the context is described in detail in the dissertations. However, while dissertations might extensively refer to current policies and practices, most of the other 
books and articles based their research setting on analysing the effects of policies and/or describing historical developments in special education and inclusion.

As for the social categories, in all articles the concepts of special needs and/or disability are covered. It should be noted, however, that perspectives differ among the articles: when an article draws from the paradigm of disability studies for example, it embeds the critique of understanding special education as medicalised. Other categories are mentioned as follows: gender, ethnicity, migrant-background or culture, and socio-economic position. Nineteen out of the 21 books and dissertations discuss special needs education from some perspective. The remaining two concentrate on adults in the school context or explicitly take a wider view to encountering diversity. Other categories besides special learning needs or disability are mentioned, especially in the dissertations. This is, again, probably due to the need to define the field thoroughly and because in dissertations there is more writing space available. When looking at the wider definition of inclusion, 11 books/dissertations mention ethnicity/migrant background or some minority ethnic group such as the Sami or Roma. Ten mention socio-economic position in some sense; eight mention gender, and two sexual orientation. There are also indeterPLQDWHFRQFHSWVVX-EKDDXIPNUKHWHURJHQHRXV SXSLOYG|was difficult to determine what exactly these referred to. It should be noted that although a definition that mentions several categories might be given, only special education inheres in the definition.

\begin{tabular}{|l|l|l|}
\hline Themes & Articles (13 in total) & $\begin{array}{l}\text { Books (21 in total out of which 12 are } \\
\text { dissertations) }\end{array}$ \\
\hline $\begin{array}{l}\text { Exploration of } \\
\text { interactions }\end{array}$ & $\begin{array}{l}\text { Five of 13 are/originally were } \\
\text { ethnographic studies, in } \\
\text { which interaction in } \\
\text { classrooms has been the } \\
\text { focus. }{ }^{4,5,8,9,10}\end{array}$ & $\begin{array}{l}\text { Thirteen } \\
\text { of } 21: 16,19,21,22,23,24,26,28,29,32,33,34 \\
\text { at least in some of the chapters observations } \\
\text { as means to provide data. Nine of these 13 } \\
\text { studies are dissertations. }\end{array}$ \\
\hline
\end{tabular}




\begin{tabular}{|c|c|c|}
\hline Socio-political Context & $\begin{array}{l}\text { Three of 13: In the } \\
\text { ethnographic studies the } \\
\text { context is described. } 8,9,10 \\
\text { Ten of } 13 \text { mention } \\
\text { international agreements; }{ }^{1,2,3} \text {, } \\
6,7,8,10,11,12,13 \text { one of them } \\
\text { PHQWLRQV2( } \& \text { 'TVVWXGL } \\
\text { international evaluation. }{ }^{12} \\
\text { National legislation is } \\
\text { mentioned in five of } 13 . .^{1,2,3,7,} \\
12\end{array}$ & $\begin{array}{l}\text { With one exception, }{ }^{16} \text { all books and } \\
\text { dissertations frame their work with national } \\
\text { legislation and/or international agreements. } \\
\text { Especially in ethnographic studies the } \\
\text { context is also understood as a description } \\
\text { of schools/pupils. This focuses mostly on } \\
\text { learning difficulties. }{ }^{15,19,20,21,22,23,26,24,28,} \\
32,33\end{array}$ \\
\hline Social Categories & $\begin{array}{l}\text { All articles discuss special } \\
\text { education from varying } \\
\text { perspectives. Gender is } \\
\text { mentioned in five of } 13 .{ }^{1,} \\
3,6,9,12 \quad \text { In seven of } 13 \\
\text { (im)migrant background, } \\
\text { ethnic background, or culture } \\
\text { is mentioned. } .^{1,3,4,6,9,10,12} \\
\text { Socio-economic position in } \\
\text { five of } \quad 13.1,3,4,6,10\end{array}$ & 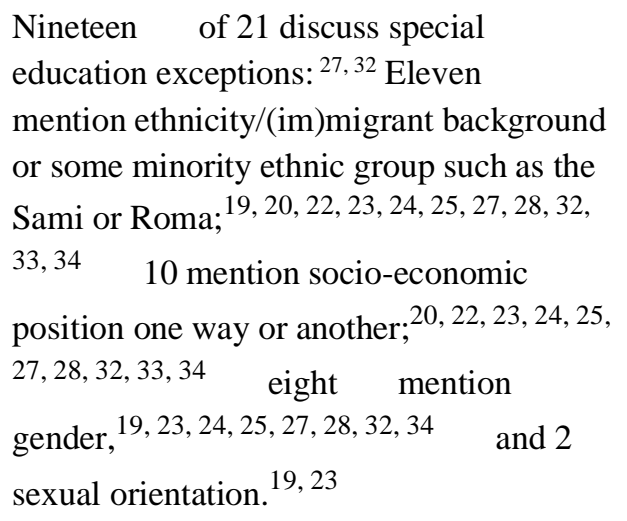 \\
\hline
\end{tabular}

Table 5. Finland: Interactions, Socio-political contextualisation and social categories. Note: The numbers in superscript refer to the reviewed publications listed in the Appendix.

\section{Iceland:}

Of the 12 articles and 10 books in the Icelandic dataset, less than a quarter of the publications rely on observations within classrooms. Four articles apply approaches such as classroom observations, video data of classroom interactions, or collaborative inquiry and action research based on classroom activity; most articles rely on interviews, surveys, or document analysis. Only one of the books reviewed mentions direct observation of classroom interactions, and this particular book is an edited compilation of 17 chapters from different Icelandic authors. This low proportion is reflective of literature that relies mainly on self-reporting, through either interviews or surveys, and which is, by design, not rooted in classrooms or school settings. 
Concerning approaches that specify a focus within a particular socio-political context, almost three-quarters of the reviewed publications describe the social context under study, but only about half of these concern social contexts in Iceland. Eight of the 12 articles situate their research specifically in Icelandic contexts, but only four of the 10 books distinctly focus on Iceland. The other four books are translated reports referring to the social context of European countries in general, drawing attention to Iceland as a participating member in larger European projects, and the remaining two focus on philosophical and instructional concepts of inclusion. In terms of specific reference to policy, again the majority of the publications (19) make specific reference to national and international educational policy. The articles mainly focus on the Icelandic National Curriculum for compulsory schooling, national and municipal inclusive education policy, and occasionally situate this within larger inclusive education policy, such as the Salamanca Statement and UNESCO guidelines. Books showed a similar focus, with a 50-50 split between publications focused on Icelandic national policy and curriculum and wider European and international policy related to inclusive education.

Among the collection of peer-reviewed literature available in the Icelandic language, the majority concentrates on social categories related to special education and mental and physical (in)abilities. The majority (15) of the articles and books reviewed specifically refer to the classification scheme of special education. Of the 12 articles reviewed, eight referred to teachers and teacher education in the field of special education and five referred specifically to special-needs students. Similarly, seven of 10 books specifically list special education in the keywords; however, only one referred to teachers or teacher education whereas four referred to students specifically. Notably, only two articles referenced linguistic and/or cultural diversity, i.e., foreign language 
learners and culturally responsive pedagogy,; and only two books referred to immigrant students. This is indicative of the dominance of special education in the discourse, along with concepts of ability/disability, and relatively little or no attention to other classifications of inclusion such as ethnicity/race/culture, gender/sexuality, and linguistic diversity. There has been a long-term focus on gender in Icelandic schools, as in other Nordic countries, but it has not been published under the rubric of inclusive education. Issues of class and socio-economic status are strikingly absent within the discourse of inclusive education.

\begin{tabular}{|c|c|c|}
\hline Themes & Articles (12 in total) & Books (10 in total) \\
\hline $\begin{array}{l}\text { Exploration of } \\
\text { interactions }\end{array}$ & Four of $12^{1,6,9,11}$ & $\begin{array}{l}\text { One of } 10 \text {, which is a collection of articles } \\
\text { on inclusive education } 9\end{array}$ \\
\hline Socio-political context & Eight of $12^{3,6,7,8,9,10,11,12}$ & $\begin{array}{l}\text { Eight of } 10^{1,2,3,4,5,6,8,9} \text {; Four of eight } \\
\text { analyse a general European social context } \\
5,6,8\end{array}$ \\
\hline Social Categories & $\begin{array}{l}\text { Mainly special education, } \\
\text { either teacher or students - } \\
\text { eight of } 12 ; 1,2,3,4,7,8,10,11 \\
\text { five refer to SEN } \\
\text { students. } 1,3,7,8,12 \quad \text { Half of } \\
\text { the articles concern teachers } \\
\text { and teacher education. } .^{2,4,5,9,} \\
10,12 \text { Two mention } \\
\text { foreign language learners } \\
\text { and culturally responsive } \\
\text { pedagogy. }\end{array}$ & $\begin{array}{l}\text { Seven of } 10 \text { specifically mention special } \\
\text { education }{ }^{2,4,5,6,7,8,9} \text { and one mentions } \\
\text { inclusive education and the origins in SEN. }{ }^{1} \\
\text { Four of } 10 \text { specifically refer to students }{ }^{2,7,8,} \\
9 \text { and two } \quad \text { of } 10 \text { refer to } \\
\text { immigrant students. }{ }^{8,9} .2 \text { refers to teacher } \\
\text { education }^{4,6}\end{array}$ \\
\hline
\end{tabular}

Table 6. Iceland: Interactions, socio-political contextualisation and social categories. Note: The numbers in superscript refer to the reviewed publications listed in the Appendix.

\section{The Netherlands:}

In general, the Dutch literature on inclusive education (10 articles, 13 books that

\section{ZHUHPDLQO\SHGDJRJLFDOPDQXVFULSWVDQGGLVVHUWDWLRQVLQFOXVLYHHGXFDV}

understood as the integration of pupils with special needs into regular education.

Overall, the literature focuses on (1) attitudes of teachers, parents and pupils, (2)

special-needs students in regular classrooms versus separate classrooms, (3) how 
teachers evaluate pupils, (4) models of disability, (5) Dutch policies of inclusive education, and (6) pedagogical tools.

Systematic cataloguing and analysing of the literature showed that there is a notable absence of attention to actual moment-to-moment interactions within classrooms. In the peer-reviewed articles, there were virtually no such analyses, except for a few indirect cases where teachers reported their experiences in the classrooms (through interviews or focus groups). Actual observations inside classrooms were referenced in only three books.

When it comes to socio-political contextualisation, inclusive education was discussed via Dutch policy and the international call for inclusion suggested by the Salamanca Statement. In almost all the peer-reviewed articles, the discussion focused on recent attempts at integration of special needs students into regular educational settings, with one paper examining the financing of inclusive education and another the gender imbalances in the sciences. ${ }^{58}$ In the books, it was less common to find discussions on the wider context of inclusive education, with only around a third of the texts having substantive references to policy, the Salamanca Statement, or the history of special education in the Netherlands.

Regarding social categories, in the articles we mainly found references to disability, behavioural problems, and language deficiency. We also found, to a lesser extent, mentions of gender, ethnicity, minorities, disadvantaged areas, and socioemotional problems. In general, books focused more on disability and behavioural problems and made almost no use of any other categories. Overall, there was a dominance of categorisations based on disability and special needs throughout the Dutch literature.

\begin{tabular}{|l|l|l|}
\hline Themes & Articles (10 in total) & $\begin{array}{l}\text { Books (15 in total out of which } 2 \text { are } \\
\text { dissertations })\end{array}$ \\
\hline
\end{tabular}




\begin{tabular}{|c|c|c|}
\hline $\begin{array}{l}\text { Exploration of } \\
\text { interactions }\end{array}$ & $\begin{array}{l}\text { Zero of } 10 \text {. (In two articles there } \\
\text { were interviews/surveys with } \\
\text { teachers about their experiences in } \\
\text { the classroom.) }\end{array}$ & $\begin{array}{l}\text { Three of 15: in three books there were } \\
\text { observations inside classrooms. (In one } \\
\text { dissertation teachers were keeping notes and } \\
\text { they were then interviewed by the researcher.) } \\
75,76,77\end{array}$ \\
\hline Context & $\begin{array}{l}\text { In nine of } 10 \text { articles, there is a } \\
\text { wider discussion of Dutch policies } \\
\text { of inclusion and/or the Salamanca } \\
\text { Statement. }{ }^{56,57,58,59,60,62,63,64,65}\end{array}$ & $\begin{array}{l}\text { In only six of } 15 \text { books there is a discussion of } \\
\text { the broader context, most often Dutch policies } \\
\text { of inclusion and special needs students. } 68,69,70 \text {, } \\
73,78,79\end{array}$ \\
\hline Categories & $\begin{array}{l}\text { In all } 10 \text { articles there are } \\
\text { categorisations, mainly regarding } \\
\text { disability and behavioural } \\
\text { problems. In one article gender is } \\
\text { the only categorisation, while in } \\
\text { two others there are references to } \\
\text { HWKQLFLW\IDQGPLQR }\end{array}$ & $\begin{array}{l}\text { In all } 15 \text { books there are categorisations, } \\
\text { mainly regarding disability and behavioural } \\
\text { problems. }\end{array}$ \\
\hline
\end{tabular}

Table 7. Netherlands: Interactions, Socio-political contextualisation and social categories. Note: The numbers in superscript refer to the reviewed publications listed in the Appendix.

\section{Discussion}

This review asked, How is the term inclusive education discussed in the scholarly

literature in Finnish, Icelandic, and Dutch between 2007 and 2018? In the academic debates across three national contexts, we have identified similarities and differences when looking at ways in which LQFOXVLYHHGXFDSHzaRQg/ng in policies (see Ozga and Jones, 2006) as well as how it has been embedded within the older framework of special education in each country.

\section{Concepts of Inclusion}

The systematic review of the scholarly local-ODQJXDJHOLWHUDWXUHRQLQFOXVLYHHGXFDW between 2007 and 2018 in Finland, Iceland and the Netherlands showed rather similar FRQFHSWXDOLVDWLRQVRILQFOXVLYHHGXFDWLRQITKHPDMRULWרRIWKHOLWHUDW HTXDWHVZLWKVSHEMPIXXHHWLRQIDQGGLVDELOLWLHVDVWKHPDLQFDWHJRU、LYH LQFOXVLRQILVWISLFDOOIVIQRQIPRXVZLWKVSHFLDOQHHGVVWXGLHVDGRSWDSVFK 
and pedagogical approach. This indicates a tendency to reduce inquiries, with few exceptions, to individuals and their characteristics. Even if a broad definition of inclusion is favoured, there are inconsistencies in how this definition is applied to the research, and only special education is consistently present in the definition. When taking into account current debates throughout Europe about growing inequality in education, ${ }^{4}$ we find this a surprising outcome of our systematic review, especially FRQVLGHULQJWKDWLQFOXVLRQHK BgefirdaHQMajor administrative bodies for decades. For instance, the EU Commission ${ }^{5}$ JRHVEHIRQGVSHFLDOQHHGVIWR conceptualise inclusive education in a comprehensive manner, referring to equality, discrimination, and social inclusion. We argue that critical, scientific scholarship should be at the forefront of such discussions by offering nuanced and multi-dimensional understandings of inclusion.

\section{Classroom Interactions}

Interpersonal classroom interaction as a focal point of studies were scarce in Iceland and the Netherlands, but in Finland dissertations tended to provide such analysis. One explanation for this scarcity is that research entailing observation and analysis of dynamic interactions in education spaces is time-consuming, and understanding how observations extend beyond individual needs into broader social realms is complex and can become expensive. Conducting interviews as the main empirical data source is less costly and less time-consuming than deep, ethnographic inquiry. In Finland, there is a long history of educational research emphasising the professional agency of the teacher,

\footnotetext{
${ }^{4}$ https://euobserver.com/education/131091

${ }^{5}$ https://ec.europa.eu/education/policies/european-policy-cooperation/inclusive-education en
} 
which may allow for more abundant funding for research focusing on classroom interactions.

\section{Socio-Political Contexts}

The larger socio-political context typically appeared as references to national legislation, teaching curricula, and/or international agreements to which the case countries were officially committed, such as the Salamanca Statement. Most research emphasised effects of policies or described historical developments in special education and inclusion rather than addressing specific social contexts. The Salamanca Statement has obviously influenced the policy landscape across all case countries, particularly as the social and political foci have moved from selective schooling to inclusive schooling. This focal shift demands that all children be able to fully participate in their local school of choice. Yet policy-level alignment has not necessarily led to all students actually being included, as has been documented for example in Iceland (Bjarnason et al., 2016; Marinósson, 2007). Instead the changes have resulted in an emphasis on a clinical service in the form of diagnosis of special needs (Jóhannesson, 2006).

\section{Social Categories}

The predominant categories used in scholarly local-ODQJXDJHOLWHUDWXUHRQLQFOXVLYH

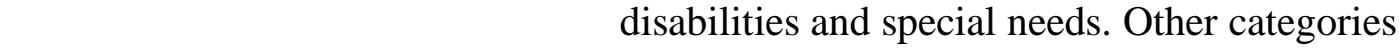
such as gender, ethnicity, linguistic background, socio-economic status (or social class), and socio-emotional problems appear in the literature, but are noticeably rare by comparison. Our results show that in all three contexts there is a lack of sensitivity to accumulated disadvantages, especially those of social class, not to mention its intersectional importance in relation to categories such as ethnicity or special needs when interpreted as individual socio-emotional problems (Allan and Harwood, 2014). 
The socio-political, historical, and geographical dimensions of inequity are marginalised in this discourse, despite being consequential in allowing for a better understanding of the effects of neo-liberalisation in education (Ball, 2006). The fact that the geography of urban school choice has given rise to further concentration of the most disadvantaged children in tKHVDPHVFKRRODUHDVPDIEHVHHQDVDUHWXUQWRWKHROGVSHFLDOVFKR ideology that inclusive education policy was designed to eliminate.

As Ainscow, Booth and Dyson (2006: 15) have pointed out, the narrowest definition of inclusion concerns students with disabilities or special educational needs. They problematised this narrow understanding, suggesting more socially engaged ideas RILQFOXVLRQZKHUHLQFOXVLRQLVXQGHUVWRRGDVDSULQFLSOHGDSSURDFKWRHG` VRFLHWIII,QVWHDGRIIRdiXsß他(1) needs, the emphasis should be on increasing the participation of all students by reducing their exclusion. Consequently, truly inclusive education would require the restructuring of policies, practices, and school cultures in order to respond to the diversity of students and to take into account all the potential sources of vulnerability.

\section{Conclusion}

This systematic review of recent literature in the local languages of Finland, Iceland and the Netherlands reveals something important about the mental structures and institutional practices enabling and delimiting scientific knowledge about inclusive education. It indicates that in all three national contexts, special education seems to be the dominant paradigm representing inclusive education. The prevailing and relatively narrow conceptualisation of this concept contrasts with a holistic understanding of inclusive education that accounts for categories such as social class, gender and race/ethnicity (Artiles et al., 2011; Ainscow et al., 2006). Considering that disadvantage is not exclusive to special education, we argue that further researching inclusive 
education requires considering and incorporating the nuances of broader classifications, especially through more fine-grained studies of inclusion. Namely, we propose three main methodological and epistemological avenues for future research on inclusive education: (1) investigating actual classroom interactions, (2) looking at how broader meso- and macro-level forces influence micro-level developments in the social context of study, and vice-versa, and (3) rigorously problematising the way in which social categories and classifications are employed and applied as analytical tools. As Artiles, Kozelski and Waitoller (2011: 5) have asserted:

\footnotetext{
address power issues at the individual, family, organisation, and system levels in explicit and systematic ways. Perhaps one of the insidious forces that blocks attaining the ideal of inclusive education is the failure of proponents to acknowledge and address the historical sediments of oppression that are layered within institutions (Artiles, Kozelski and Waitoller, 2011: 5).
}

«7KHJUHDWHVWFKDOOHQJHWRLQFOXVLYHHGXFDWLRQLVDUJXDEOIRXQGLQWKHIDI

We suggest that researchers adopt a more critical approach by considering schools as middleclass-favouring institutions (Reay et.al., 2011; Weis, 2008), where locally-born, i.e., white, pupils' backgrounds more easily align with the applied discourse and linguistic features as well as the cultures, conduct, and character of the school system. The pupils that do not easily align ZLWKWKHVHUHTXLUHPHQWVDUHRIWHQFRQVWUXFWHGDVRWKHUIRUDVSUREOHPDWLFTIRU VSHEDOQHHGVI'XGUtrlling, 2004). It is important to critically consider how the hegemonic school culture may create otherness among those who do not fit the local ideal. While Finland, Iceland, and the Netherlands may be generally perceived as supporting egalitarian and meritocratic educational systems, there are clear indications that in these settings inequality is on the rise (Dovemark et al., 2018; Kuyvenhoven \& Boterman, 2020; Bernelius and Vilkama, 2019). Considering these processes, future research on inclusive education can benefit from socio-politically informed, micro-level intersectional studies on disadvantage and marginalisation that remain reflexive regarding schemes of categorisation and/or 
classification. This can counterbalance existing research that has thus far been conceptualised mainly through the lens of special education needs and disabilities. The value of our systematic multilingual literature review lies in its ability to highlight the need to address not just the intersections of social class, gender, ethnicity, geography, and exclusion in these three national spheres $\dagger$ but also the mental structures enabling and constraining research on inclusion in Northern Europe and beyond.

\section{References}

Authors. In press, 2020, 2018, 2017, 2016, 2003.

Ahonen S (2003) Yhteinen koulu: Tasa-arvoa vai tasapäisyyttä? Koulutuksellinen tasa-arvo Suomessa Snellmanista tähän päivään [A common school for all? Educational equality in Finland from Snellman to today], Tampere: Vastapaino.

Ahtiainen R (2017) Shades of change in Fullan's and Hargreaves's models: Theoretical change perspectives regarding Finnish special education reform. Helsinki: University of Helsinki.

Ainscow M, Booth T and Dyson A (2006) Improving schools, developing inclusion. London: Routledge.

Allan J and Slee R †'RLQJ,QFOXVLYH(GXFDWLRQ5HVHDUFK·,Q*DEHO6DQG'DQIRUWK6 (eds) Disability and the Politics of Education: An International Reader. New York: Peter Lang, pp. 141-159.

Amor A M, Hagiwara M, Shogren K A, Thompson J R, Verdugo M Á, Burke K M and Aguayo V (2019) International Perspectives and Trends in Research on Inclusive Education: A Systematic Review. International Journal of Inclusive Education 23(12): 1277-1295.

Antikainen A (2006) In search of the Nordic model in education. Scandinavian journal of educational research, 50(3): 229-243. 
Artiles A J, Kozleski E B and Waitoller F R (2011) Inclusive Education: Examining Equity on Five Continents. Cambridge, Massachusetts: Harvard Education Press.

Ball S J (2006) Education Policy and Social Class. London: Routledge.

Barton L (2004) The Politics of Special Education: A Necessary or Irrelevant Approach? In: Ware L (ed) Ideology and the Politics of (In)Exclusion. New York: Peter Lang, pp. 6375.

Basic Education Act BEA 628/1998. (Accessed 16 April

2019). https://www.finlex.fi/fi/laki/ajantasa/1998/19980628

Basic Education Act BEA 642/2010. (Accessed in 16 April 2019).

https://www.finlex.fi/fi/laki/ajantasa/1998/19980628

Basic Education Act BEA 642/2010. https://www.finlex.fi/fi/laki/ajantasa/1998/19980628 (accessed 16 April 2019).

Berhanu G and Dyson A (2012) Special Education in Europe, Overrepresentation of Minority Students. In: Banks J (ed) Encyclopedia of Diversity. Thousand Oaks: Sage, pp. 20702073.

Bernelius V (2013) Eriytyvät kaupunkikoulut. Helsingin peruskoulujen oppilaspohjan erot, perheiden kouluvalinnat ja oppimistuloksiin liittyvät aluevaikutukset osana kaupungin eriytymiskehitystä. [Schools drifting apart: The urban dynamics of school segregation, school choices and neighbourhood effects]. Helsinki City Urban Facts Research Publications 2013:1.

\%HUQHOLXV9DQG9DDWWRYDDUD0\&KRLFHDQGVHJUHJDWLRQLQWKHPRVWHJDOLWDULDQ

Cumulative decline in urban schools and neighbourhoods of Helsinki, Finland. Urban Sstudies, 53(15): 3155-3171. 
Bernelius V and Vilkama K (2019) Pupils on the move: School catchment area segregation and residential mobility of urban families. Urban Studies, Advance online publication. doi.org/10.1177/0042098019848999.

Bjarnason D S, Gunnpórsdóttir H and Jónsson Ó P (2016) Skóli margbreytileikans: Menntun og manngildi i kjölfar Salamanca [The Inclusive School: Education and Human Values in the Wake of Salamanca]. Reykjavík: Háskólaútgáfan.

Boterman WR (2018) School segregation in the free school choice context of Dutch cities. In: Bonal X and Bellei C (eds), Understanding School Segregation: Patterns, Causes and Consequences of Spatial Inequalities in Education. London: Bloomsbury, pp. 155-178.

Cooc N and Kiru E W (2018) Disproportionality in Special Education: A Synthesis of International Research and Trends. The Journal of Special Education, 52(3): 163-173. doi:10.1177/0022466918772300

Dudley-Marling C. (2004) The Social Construction of Learning Disabilities. Journal of Learning Disabilities, 37(6): 482-489. doi:10.1177/00222194040370060201

Dudley-Marling D and Baker D (2012) The Effects of Market-Based School Reforms on Students with Disabilities. Disability Studies Quarterly, 32(2): 1-19.

'XVWPDQQ\&3XKDQL3\$DQG6FK|QEHUJ87KHORQJ(WHUPHIIHFWVRIHDUOIWUDFNFKRLFH The Economic Journal 127(603): 1348-1380.

Florian L (2019) On the necessary co-existence of special and inclusive education. International Journal of Inclusive Education, 23:(7-8): 691-704, DOI: $10.1080 / 13603116.2019 .1622801$

Francis B, Hodgen J, Craig N, Taylor B, Archer L, Mazenod A, Tereshchenko A and Connolly 3 7HDFKHU 4XDOLWII DQG \$WWDLQPHQW *URXSLQJ 7KH 5ROH RI-\$dWdбLQ Teacher Deployment in Social and Educational Inequality. Teaching and Teacher Education 77: 183-192. 
Gibson S (2015) When rights are not enough: What is? Moving towards new pedagogy for inclusive education within UK universities. International Journal of Inclusive Education 19(8): 875-886.

Göransson K and Nilholm C (2014) Conceptual Diversities and Empirical Shortcomings - A Critical Analysis of Research on Inclusive Education. European Journal of Special Needs Education 29(3): 265-280.

Hamre B, Morin A and Ydesen C (2018) Testing and Inclusive Schooling: International Challenges and Opportunities. New York: Routledge.

Hanushek EA and Woessmann L (2006) Does educational tracking affect performance and

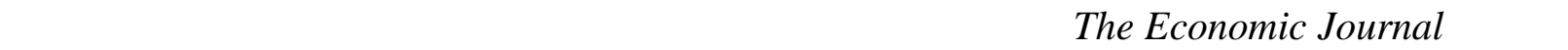
116(510): C63-C76.

Hardy I, \& Woodcock S (2015) Inclusive education policies: Discourses of difference, diversity and deficit. International Journal of Inclusive Education 19(2): 141-164.

Hienonen N, Lintuvuori M, Jahnukainen M, Hotulainen R and Vainikainen M P (2018) The Effect of Class Composition on Cross-Curricular Competences - Students with Special Educational Needs in Regular Classes in Lower Secondary Education. Learning and Instruction 58: 80-87.

-yKDQQHVVRQ ,“ \$6WURQJ ,QGHSHQGHQW \$EOH WR /HDUQ 0RUH«I[·,QFOXVLRQ DQG WKH

Construction of School Students in Iceland as Diagnosable Subjects. Discourse: Studies in the Cultural Politics of Education 27(1): 103-119. doi:10.1080/01596300500510328

Johnston O and Wildy H (2016) The effects of streaming in the secondary school on learning outcomes for Australian students-A review of the international literature. Australian Journal of Education 60(1): 42-59. 
Keskiner E (2015) Is it Merit or Cultural Capital? The role of parents during early tracking in Amsterdam and Strasbourg among descendants of immigrants from Turkey. Comparative Migration Studies 3(1): 1-19.

\section{.ORRVWHUPDQ 5DQG 'H*UDDI30 1RQ(SURPRWLRQRU HQUROPHQWLQDORZHUWUDFN" 7KH} influence of social background on choices in secondary education for three cohorts of Dutch pupils. Oxford Review of Education 36(3): 363-384.

Kuyvenhoven J and Boterman WR (2020) Neighbourhood and school effects on educational inequalities in the transition from primary to secondary education in Amsterdam. Urban Studies. Advanced online publication. DOI: 10.1177/0042098020959011.

Lundahl L (2016) Equality, Inclusion and Marketization of Nordic Education: Introductory Notes. Research in Comparative and International Education 11(1): 3-12. doi:10.1177/1745499916631059

Magnússon G (2019) Inclusive Education and School Choice Lessons from Sweden. European Journal of Special Needs Education. Advanced online publication. doi:10.1080/08856257.2019.1603601

0DULQyVVRQ*/DQG\%MDUQDVRQ'6 6SHFLDO(GXFDWLRQ7RGDILQ,FHODQG·,Q5RWDWRU।

AF, Bakken JP, Obiakor FE and Burkhardt S (eds) Special Education International Perspective: Practices Across the Globe Advances. New York: Emerald Group Publishing, pp. 271-309

Marinósson GL (2007) Tálmar og takifari [Barriers and opportunities]. Reykjavík: Háskólaútgáfan.

Mazenod A (2017) Lost in Translation? Comparative Education Research and the Production of Academic Knowledge. Compare: A Journal of Comparative and International Education 48(2): 189-205. 
Mittler P (2008) Planning for the Future: Planning for the 2040s: Everybody's Business. British Journal of Special Education 35(1): 3-10. doi:10.1111/j.1467-8578.2008.00363.x

O'Rourke J (2015) Inclusive Schooling: If It's so Good - Why Is It Sso Hard to Sell? International Journal of Inclusive Education 19(5): 530-546. doi:10.1080/13603116.2014.954641

Ozga J and Jones R (2006) Travelling and embedded policy: the case of knowledge transfer. Journal of education policy 21(1): 1-17.

Putnam R D (2016) Our kids: The American Dream in Crisis. Simon and Schuster.

Raffo C and \& Gunter H (2008) Leading schools to promote social inclusion: Developing a conceptual framework for analysing research, policy and practice. Journal of Education Policy 23(4): 397-414. doi:10.1080/02680930801923799

Reay D, Crozier G and James D (2011) White Middle Class Identities and Urban Schooling. Hampshire: Palgrave Macmillan.

Rezai S, Crul M, Severiens S and Keskiner E (2015) Passing the Torch to a New Generation: Educational Support Types and the Second Generation in the Netherlands. Comparative Migration Studies 3(1): 1-12

Richardson J and Powell J (2011) Comparing Special Education: Origins to Contemporary Paradoxes. Stanford: Stanford University Press.

Seppänen P (2006) Kouluvalintapolitiikka perusopetuksessa: Suomalaiskaupunkien koulumarkkinat kansainvälisessä valossa [School choice policy in comprehensive education: School markets in the Finnish cities in international light]. Turku: Suomen kasvatustieteellinen seura.

Sigurðardóttir A K, Guðjónsdóttir H and Karlsdóttir J (2014) The Development of a School for all in Iceland: Equality, Threats and Political Conditions. In: Blossing U, Imsen G and Moos L (eds) The nordic education model: 'A school for all' encounters neo-liberal policy. London: Springer, pp.95-113. 
Slee R (2011) The Irregular School: Exclusion, Schooling and Inclusive Education. New York: Routledge.

Slee R (2013) How do we make inclusive education happen when exclusion is a political predisposition? International Journal of Inclusive Education 17(8): 895-907.

Smyth J (2017) Social inclusion. Oxford Research Encyclopedia of Education.

Statistics Finland (2017) Appendix table 1. Comprehensive school pupils having received intensified or special support. https://www.stat.fi/til/erop/2017/erop_2017_2018-0611_tau_001_fi.html (accessed 23 April 2019).

Steiner-Khamsi G (2009) Comparison: Quo Vadis? In: International handbook of comparative education. Springer: Dordrecht, pp.1141-1158.

Thomas G (2013) A review of thinking and research about inclusive education policy, with suggestions for a new kind of inclusive thinking. British Educational Research Journal 39(3): 473-490. doi:10.1080/01411926.2011.652070

Tomlinson S (2017) A sociology of special and inclusive education: Exploring the manufacture of inability. London: Routledge.

UNESCO (1994) The Salamanca Statement and Framework for Action on Special Needs Education. Paris: Unesco.

UNESCO (2015) Education 2030: Incheon Declaration and Framework for Action for the implementation of Sustainable Development Goal 4: Ensure inclusive and equitable quality education and promote lifelong learning.

https://unesdoc.unesco.org/ark:/48223/pf0000245656 [Accessed 24 March 2020]

Van De Werfhorst, HG and Van Tubergen F (2007) Ethnicity, schooling, and merit in the Netherlands. Ethnicities 7(3): 416-444.

Van De Werfhorst, HG (2015) Institutional contexts for socioeconomic effects on schooling outcomes. In: Scott RA and Kosslyn SM (eds) Emerging Trends in the Social and 
Behavioral Sciences: An Interdisciplinary, Searchable, and Linkable Resource. Wiley, pp.1-8.

Vincent C, Ball S J, Rollock N and Gillborn D (2013) Three generations of racism: Black middleclass children and schooling. British Journal of Sociology of Education 34(5-6): 929946.

Waitoller F R and Artiles A J (2013) A Decade of Professional Development Research for Inclusive Education: A Critical Review and Notes for a Research Program. Review of Educational Research 83(3): 319-356.

Weis L (2008) The way class works: readings on school, family and the economy. New York: Routledge.

Woessmann L (2016) The importance of school systems: Evidence from international differences in student achievement. Journal of Economic Perspectives 30(3): 3-32.

Zweers I (2018) $\ddagger 6 K D S H V R U W L Q J \cdot V W X G H Q W V I R U V S H F L D O H G X F D W L R Q V H U Y L F h E k i t \$ V W X G R Q S O D$ choices and social-emotional and academic functioning of students. $\mathrm{PhD}$ thesis, Utrecht University, The Netherlands. 